\title{
UM OLHAR VIGOTSKIANO NA FORMAÇÃO DE CONCEITOS EM CIÊNCIAS E BIOLOGIA
}

\author{
A LOOK AT FORMING CONCEPTS VIGOTSKYAN SCIENCES AND BIOLOGY
}

\author{
Rosa Andréa Lopes de Souza ${ }^{1}$
}

RESUMO: Este trabalho busca apresentar relações entre o desenvolvimento dos conceitos científicos na infância, proposto por Lev Semenovich Vigotski (1896-1934) psicólogo bielorusso, em seu livro A construção do pensamento e da linguagem, e a formação de conceitos científicos na aprendizagem de evolução biológica por alunos do ensino fundamental - ciclo final - e alunos do ensino médio, estabelecendo possíveis relações entre a aprendizagem científica da criança no início da sua vida escolar e aprendizagem de ciências do jovem nos referidos ciclos de ensino. Para isso, analisamos o capítulo do livro de Vigotski que versa sobre o assunto sob as propostas de diferentes trabalhos de pesquisa tanto na área da aprendizagem quanto na do ensino dos conteúdos científicos pertinentes.

Palavras-chave: Vigotski. conceitos científicos. evolução biológica. aprendizagem e ensino de ciências.

ABSTRACT: This paper aims to present relations between the development of scientific concepts in childhood proposed by Lev Semenovich Vigotski (1896-1934) Belarusian psychologist, in his book A construção do pensamento e da linguagem, and the formation of scientific concepts in the learning of biological evolution for elementary students - final cycle - and high school students, establishing possible relationships between the scientific learning of the child at the beginning of their school life and learning of the young science of teaching in these cycles. For this, we analyzed the Vigotski chapter of which deals with the subject under the different proposals for research projects both in learning and teaching in the relevant scientific content.

Keywords: Vigotski. scientific concepts. biological evolution, learning and teaching science.

\footnotetext{
${ }^{I}$ Mestra em Ensino de Ciências - modalidade Biologia - pelo Programa de Pós-Graduação Interunidades em Ensino de Ciências da Universidade de São Paulo (USP). Filiada à linha de pesquisa 'História, Filosofia, Ciência e Cultura no Ensino de Ciências, pela Universidade de São Paulo'. Pesquisadora, no período de 201 a 2017, do Laboratório de História da Biologia e Ensino (LHBE-USP), coordenado pela Profa. Dra. Maria Elice Brzezinski Prestes. Atualmente, é pesquisadora integrante do Grupo de Estudos e Pesquisas em Ensino de Biologia (GEPEB-FE-USP), coordenado pela Profa. Dra. Sílvia Luzia Frateschi Trivelato. Especialista em Ciências Ambientais pela Universidade São Francisco (USF). Graduada em Ciências Biológicas pela Universidade São Francisco (USF). Graduada em Pedagogia pelo Centro Universitário Amparense (UNIFIA). Professora de Biologia e Ciências da Rede Particular de Ensino do Estado de São Paulo. E-mail: rosa.andrea@usp.br.
} 


\section{INTRODUÇÃO}

O presente trabalho busca investigar a possibilidade de relação entre o desenvolvimento dos conceitos científicos na infância proposto por Vigotski em seu livro A construção do pensamento e da linguagem (2010) e a formação de conceitos (de ciência) ligados à evolução biológica por estudantes do ciclo final do ensino fundamental e ensino médio. Essa proposta pretende analisar e estabelecer relações fundamentais entre os conceitos científicos e espontâneos que o estudante em início de formação escolar pode apreender no processo de aprendizagem e posterior transformação e aprofundamento desses conceitos ao longo de sua trajetória escolar no aprendizado dos conteúdos de ciência.

A importância que justifica nosso trabalho, baseia-se no reconhecimento por parte dos professores de Ciências e Biologia, das dificuldades que os alunos apresentam em promover a transposição natural de conceitos espontâneos, principalmente, relacionados ao objeto de nosso estudo que é a evolução biológica e conteúdos afins aos conceitos científicos vinculados a esse conteúdo de ensino. $O$ pensamento evolutivo darwinista, principal referencial na transmissão de conceitos científicos da evolução biológica aos estudantes brasileiros, apresenta nesse sentido grande importância no ensino, tais como, apresentação de modelos explicativos da biologia, educação para a cidadania, especialmente para tomada de decisões em situações sócio-científicas, comprometimento na compreensão satisfatória de diversos processos biológicos importantes como pandemias provocadas por vírus, em especial, nos dias atuais, as polêmicas negacionistas envolvendo a pandemia do COVID-I9, melhoramento genético de plantas e animais, resistência bacteriana a antibióticos, filogenética auxiliando o monitoramento de doenças e identificação de espécies para finalidades médicas, farmacológicas e conservação, bioinformática e biotecnologia.

Apesar dessa importância, os resultados acerca de seu ensino e aprendizagem são relativamente desanimadores. Mesmo após instrução formal sobre o tema, algo que ocorre, geralmente, nos ciclos finais do ensino fundamental e ao longo do ensino médio, a persistência de dificuldades por parte dos alunos em resolver e interpretar fenômenos biológicos em termos darwinistas permanece (CLOUGH \& WOOD-ROBINSON, 1985; BISHOP \& ANDERSON, 1990; BIZZO, 1994; DEMASTES, SETTLAGE \& GOOD, 1995; 
JENSEN \& FINLEY, I996; SINCLAIR, PENDARVIS \& BALDWIN, I997; ALTERS \& NELSON, 2002).

Muitos estudos que já se propuseram a pesquisar os fatores que indicassem essa dissonância entre a instrução formal dos conceitos evolutivos, trabalhados no plano social da sala de aula, entre professores e alunos e a persistência das dificuldades dos mesmos em resolver e interpretar fenômenos biológicos em termos darwinistas encontraram como possíveis causas a incompreensão de conceitos centrais que estruturam a teoria darwinista da evolução (FERRARI \& CHI, 1998), rejeição aos aspectos metafísicos dessa teoria, especialmente, envolvendo conflitos com concepções de natureza na visão de mundo dos estudantes como aquelas pautadas nas religiões cristãs (COBERN 1994, 1996; SMITH, 1994; BREM, RANNEY \& SCHINDEL, 2003; SEPULVEDA \& EL-HANI, 2004, 2006), frequência de visões inadequadas sobre a Natureza da Ciência entre estudantes e professores (SMITH, SIEGEL \& MCINERNEY, 1995).

Esses fatores explicam em parte as dificuldades acadêmicas dos alunos sobre o tema, mas não explicam o porquê dos conceitos espontâneos utilizados nas explicações dos estudantes, sobrepujar os conceitos científicos, impedindo um paralelismo de boa convivência entre eles.

O presente trabalho traz inicialmente uma breve explanação da formação dos conceitos científicos por Vigotski, referencial teórico que mais nos chamou atenção neste processo por escrutinar a gênese dos conceitos espontâneos e científicos na infância, sem com isso obviamente esgotar o assunto que pela essência é fértil demais, mas desta forma estabelecemos um recorte na análise facilitando o aprofundamento. Posteriormente procuramos discutir a aprendizagem e o ensino de ciências e biologia no panorama escolar brasileiro com base nesse desenvolvimento proposto por Vigotski para finalmente estabelecermos possíveis obstáculos à aprendizagem de conceitos em Ciências e Biologia.

\section{DESENVOLVIMENTO DOS CONCEITOS CIENTÍFICOS NA INFÂNCIA}

O desenvolvimento dos conceitos científicos na idade escolar é, antes de tudo, uma questão prática de imensa importância - talvez até primordial - do ponto de vista das tarefas que a escola tem diante de si quando inicia a criança no sistema de conceitos científicos (Vigotski, 2010, p. 240). 
Ao abrir desta forma o capítulo sobre o desenvolvimento de conceitos científicos na infância, Vigotski logo de pronto demonstra a seriedade que deve ser tratado o tema pela escola e o seu papel nesse desenvolvimento. Demonstra, além de tudo, que é a partir desse desenvolvimento científico e, sejamos claros quanto a isso, quando ele diz científico ele não restringe ao ensino de ciências naturais, mas, obviamente a todas as disciplinas curriculares que envolvem peculiaridades de suas ciências próprias, que a criança poderá em sua formação escolar ter pleno desenvolvimento conceitual. Enfim, Vigotski nos convida para essa aventura no entendimento, a partir de suas pesquisas e experiências empíricas, da gênese do desenvolvimento dos conceitos científicos na infância.

Vigotski ao analisar uma investigação experimental, proposta por seu discípulo leningrandese, J. I. Chif, em sua dissertação, que teve por finalidade o estudo comparado do desenvolvimento dos conceitos espontâneos e científicos na idade escolar, e como principal objetivo verificar experimentalmente a hipótese de trabalho do próprio Vigotski aplicada à via original de desenvolvimento percorrida pelos conceitos científicos em comparação com os espontâneos, percebe nessa experimentação desvio das premissas básicas segundo as quais os conceitos - significado das palavras - se desenvolvem, dando por ilegítimo a transferência de conclusões baseadas em conceitos espontâneos para conceitos científicos.

Vigotski (2010, p. 245) propõe então, ele mesmo, uma metodologia experimental que venha a responder questões do tipo: Como se desenvolvem os conceitos científicos na mente de uma criança em processo de aprendizagem escolar? Em que relação se encontram os processos de ensino $e$ aprendizagem de conhecimentos propriamente ditos e os processos de desenvolvimento interior do conceito científico na consciência da criança? Coincidem entre si, sendo, essencialmente, apenas duas faces de um mesmo processo? O processo de desenvolvimento interior do conceito sucede o processo de aprendizagem, como sombra lançada pelo objeto, sem coincidir com ele, mas reproduzindo com precisão e repetindo o seu movimento, ou entre ambos os processos existem relações infinitamente mais complexas e sutis que só podem ser estudadas por meio de investigações especiais?

São questionamentos profundos e ao longo do capítulo Vigotski procura respondêlos todos, com vistas sempre baseadas na análise psicológica e pedagógica do que já foi proposto na literatura especializada da época, sobre essas perguntas até o momento de sua 
investigação, comparando-as, fervorosamente, com seus dados experimentais e sua análise profissional.

Interessa-nos sobremaneira as análises de Vigotski que envolvem a formação de conceitos e o impacto desse desenvolvimento na criança em idade escolar. Vigotski propõe que um conceito é mais do que a soma de certos vínculos associativos formados pela memória, é mais do que um simples hábito mental; é um ato real e complexo de pensamento que não se aprende por mera memorização, só podendo ser realizado quando o próprio desenvolvimento mental da criança já houver atingido o seu nível mais elevado. Enfim, os conceitos psicologicamente concebidos evoluem como significados das palavras, são em termos psicológicos, atos de generalizações.

Nesse sentido é de importância fundamental para Vigotski e, particularmente, concordamos plenamente, que tanto psicólogos quanto pedagogos e professores tenham noção que quando uma criança apreende uma palavra nova ligada a determinado significado, o desenvolvimento conceitual dessa palavra para a criança está apenas começando; no início ela é uma generalização do tipo mais elementar que, à medida que a criança se desenvolve, é substituída por generalizações de um tipo cada vez mais elevado, chegando nesse processo na formação dos verdadeiros conceitos. Não cabendo aqui concepções segundo as quais os conceitos são apreendidos pela criança em forma pronta e acabada no processo de aprendizagem escolar e assimilados da mesma maneira como se assimila uma habilidade intelectual qualquer (Vigotski, 2010, p. 249).

Porém, nos cabe agora verificar como Vigotski procura resolver o problema do desenvolvimento dos conceitos científicos. Desenvolvimento que se forma justamente no processo de ensino de um determinado sistema de conhecimento científico à criança. Primeiramente Vigotski procura elucidar se há uma diferença objetiva entre os conceitos espontâneos - tidos como aqueles que se originam da experiência vital direta da criança - e os conceitos científicos, para na sequência estabelecer se ambos os processos de formação de conceitos admitem estudo comparado. Vigotski compara intensamente as pesquisas de Jean Piaget (1896-1980) sobre o assunto com suas investigações e estudos empíricos, delimitando profundas diferenças entre seu trabalho e o do pesquisador suíço. Aliás, os objetivos da pesquisa e, particularmente, da construção da hipótese de trabalho sobre o desenvolvimento 
dos conceitos científicos na infância, buscam superar, palavras de Vigotski, os erros fundamentais de uma das teorias modernas mais fortes.

Reiteramos que nessa seção nos interessa analisar as pesquisas de Vigotski sobre os temas acima tratados, portanto, não exporemos os trabalhos de Piaget que Vigotski tão detalhadamente estudou em seu próprio livro.

Para Vigotski o desenvolvimento dos conceitos espontâneos e científicos são processos intimamente interligados, que exercem influências um sobre o outro, sendo o limite - se existir - que separa ambos os conceitos, extremamente fluido. Em sua experiência verifica que o desenvolvimento dos conceitos científicos só se torna possível depois que os conceitos espontâneos da criança atingiram um nível próprio do início da idade escolar e que o surgimento de conceitos de tipo superior, como o são os conceitos científicos, influenciam o nível dos conceitos espontâneos anteriormente constituídos, simplesmente por estes não estarem encapsulados na consciência da criança, não estando assim separados por muralhas intransponíveis, incapazes de se processarem mutuamente. Esse intercâmbio de influências entre os conceitos espontâneos e científicos redundam no desenvolvimento de um processo único de formação de conceitos, que se realiza sob diferentes condições internas e externas mas continua indiviso por sua natureza e não se constitui da luta, do conflito e do antagonismo entre duas formas de pensamento que por fim se excluem. Muito ao contrário disso, entre os processos de aprendizagem e de desenvolvimento na formação dos conceitos devem coexistir não antagonismo, mas relações de caráter infinitamente mais complexo e positivo.

Assim, a aprendizagem constitui-se em uma das principais fontes de desenvolvimento dos conceitos infantis e poderosa força orientadora desse processo de múltiplas influências entre os conceitos espontâneos e científicos. Vigotski se baseia no fato de que a aprendizagem na idade escolar é o momento decisivo e determinante de todo o destino do desenvolvimento intelectual da criança, inclusive do desenvolvimento dos seus conceitos. Os caminhos da aprendizagem percorridos para a formação dos conceitos espontâneos e científicos são como já afirmamos diferentes. O surgimento e constituição dos conceitos científicos na criança se apoiam no processo de aprendizagem escolar por via inteiramente diferente que no processo de experiência pessoal da criança com os conceitos 
espontâneos. Daí toda importância que Vigotski apresenta sobre o papel da escola no desenvolvimento dos conceitos infantis.

É nesse meio social - escola - que a criança tomará para si, através da aprendizagem, generalizações capazes de interpretar a relação entre os conceitos espontâneos que possui e os científicos construídos em sua vida acadêmica, mesmo que isso ocorra por noções gerais e complexas, de forma não-conscientizada, ou seja, como outra orientação da atividade da consciência. É na idade escolar que a atenção e a memória passam a ser conscientizadas e arbitrárias. $\mathrm{Na}$ escola a criança pode perceber as coisas, mesmo que estas sejam conhecidas por elas, de modo diferente, significando com isso que também pode ganhar outras possibilidades de agir em relação a elas. É a tomada de consciência e apreensão.

\section{ENSINO DE CIÊNCIAS E BIOLOGIA}

Muitas são as pesquisas e estudos na área de ensino e aprendizagem em Ciências e Biologia. Inúmeras são as ideias de estratégias de aulas para a melhoria do ensino dessas disciplinas. Inesgotáveis análises focadas naquilo que ou o estudante sabe ou não sabe sobre um determinado tema. Todas essas pesquisas são infinitamente válidas àquilo que se propõem. Este trabalho se configura como uma oportunidade de compartilhar ideias que possam de alguma forma contribuir para a eficiência da docência nas disciplinas de Ciências e Biologia.

Primeiramente investigamos entre os muitos trabalhos de pesquisa acadêmica as principais estratégias pedagógicas que os professores de Ciências vêem fazendo uso e percebemos assim como BASTOS (2009, p.18) que o debate acadêmico em torno do Ensino de Ciências tem sido, nos últimos anos, fortemente influenciado por abordagens construtivistas que tomam como referência analogias ou relações que são feitas entre os processos de produção de conhecimentos na ciência e no indivíduo. Assim, o processo de produção de conhecimentos na ciência atua como fonte de inspiração para a proposição de modelos de aprendizagem e modelos de ensino, pelo forte impacto que provocam nas comunidades de educadores.

E assim mesmo, como apontam BELL e PEARSON (1992), não é possível mudar o que normalmente os professores fazem na sala de aula (a simples transmissão de saberes já 
elaborados) sem transformar a sua epistemologia, as suas concepções acerca de como o conhecimento científico é construído, ou seja, as suas ideias sobre a Ciência.

No panorama da educação básica brasileira podemos reconhecer uma crescente preocupação em relação às diretrizes do ensino de Ciências e Biologia. No manual “Orientações Curriculares para o Ensino Médio" (Ciências da Natureza, Matemática e suas Tecnologias), o fragmento abaixo expressa bem essa tentativa:

\begin{abstract}
Nas últimas décadas, o ensino de Biologia vem sendo marcado por uma dicotomia que constitui um desafio para os educadores. (...) Assim, um ensino pautado pela memorização de denominações e conceitos e pela reprodução de regras e processos - como se a natureza e seus fenômenos fossem sempre repetitivos e idênticos - contribui para a descaracterização dessa disciplina enquanto ciência que se preocupa com os diversos aspectos da vida no planeta e com a formação de uma visão do homem sobre si próprio e de seu papel no mundo. (MEC, 2006)
\end{abstract}

Pelo expresso no documento fica evidente que além da preocupação em relação às diretrizes escolares o ensino dever ser voltado a uma educação científica integradora e cooperativa, deixando no passado aqueles conteúdos baseados em fatos desconexos e descontextualizados com as concepções cotidianas dos alunos.

No universo da Biologia é comum entre os especialistas em ensino de essa disciplina considerar a teoria da evolução darwiniana como um eixo centralizador e integrador das demais ciências biológicas. De acordo com MEYER e EL-HANI (2005) a maior parte da comunidade científica considera o pensamento evolutivo o eixo central e unificador das Ciências Biológicas, sendo entendida como um elemento indispensável para a compreensão apropriada da grande maioria dos conceitos e das teorias encontrados nessas ciências.

Diversos profissionais e associações, no mundo todo, se preocupam com a qualidade do ensino da evolução biológica. No Brasil, esse assunto é objeto de reflexão do governo, de diversos tipos de associações, e de educadores. Os Parâmetros Curriculares Nacionais recomendam que todas as ciências biológicas sejam conectadas transversalmente por um eixo ecológico-evolutivo. Os Programas Nacionais do Livro Didático têm proporcionado uma melhoria significativa na qualidade dessas obras, aprimorando a correção conceitual e metodológica em várias disciplinas, inclusive a evolução biológica. Sociedades científicas e não científicas têm se manifestado através da imprensa e, principalmente, da internet, onde há vários sites com materiais e informações sobre evolução biológica. A continuidade desses investimentos é essencial para ajudar os professores a utilizar corretamente a teoria 
evolutiva como eixo transversal do processo de ensino-aprendizagem das ciências biológicas, conforme recomendado.

Desde que a teoria da Evolução, segundo MARANDINO (2009, p. 29) assumiu essa posição central nas Ciências Biológicas, tanto os pesquisadores do ensino quanto os professores da educação básica passaram a reconhecer a importância dessa temática nas disciplinas escolares Ciências e Biologia. Expressando-se além dos documentos curriculares oficiais já citados - Parâmetros Curriculares Nacionais para os ensinos fundamental e médio - como na produção de autores nacionais e estrangeiros, os quais reafirmam a influência da teoria da Evolução na organização dos currículos escolares.

Estando assim organizados os currículos escolares orientam o ensino na educação básica brasileira. Ainda MARANDINO (2009, p. 87) provoca mais a discussão ao expor e alertar sobre as inúmeras críticas imputadas historicamente ao ensino das disciplinas Ciências e Biologia, independentemente da temática dessas disciplinas, acusadas de privilegiar a descrição e a memorização, apesar das várias pesquisas e estudos acadêmicos voltados especialmente a analisar a prática docente com intenção clara de reverter esse quadro.

Caso esse ciclo vicioso se mantenha no ensino dessas e de outras disciplinas em Ciência, elas podem perigosamente ser associadas como pouco significativas para além do próprio universo acadêmico, descaracterizando o sentido das propostas em documentos oficiais da educação. Este é um desafio que não podemos fugir.

\section{POSSÍVEIS OBSTÁCULOS À APRENDIZAGEM DE CONCEITOS EM CIÊNCIAS E BIOLOGIA}

A partir da leitura integral do livro de Vigotski, A construção do pensamento e da linguagem, e mais especialmente, da leitura do capítulo sobre o desenvolvimento dos conceitos científicos na infância, pensamos em estabelecer relações entre esse processo e o ensino de Ciências e Biologia atualmente.

Reconhecendo o impacto das estratégias construtivistas de ensino e aprendizagem nas comunidades de educadores, a divulgação dos estudos do pensamento de Vigotski revela-se muito pertinente aos professores interessados em conhecer ou pelos menos 
entender em parte o caminho percorrido pelo estudante que chega até suas mãos nos ciclos finais do ensino fundamental e médio.

Quando esses alunos chegam aos anos finais do ensino fundamental e ao ensino médio, são adolescentes que, psicologicamente, ainda estão em estado de amadurecimento do pensamento, não sendo em hipótese alguma, indivíduos em um período de conclusão, mas de crise, no que tange à formação superior de pensamento, acessível à mente humana, essa idade é também transitória, e o é em todos os outros sentidos e funções orgânicas. Esse caráter transitório do pensamento do adolescente torna-se sobretudo nítido quando não tomamos o seu conceito em forma acabada, mas em ação e, para Vigotski, o conceito em ação no adolescente dá fundamento à nova forma de pensamento e ilumina o caráter do conjunto da sua atividade intelectual, iluminando também o desenvolvimento da personalidade e da concepção de mundo desse adolescente.

Esses adolescentes ao iniciarem sua vida escolar passaram por intensas transformações internas e externas, de âmbitos psicológicos já expostos anteriormente, com influências contundentes relacionadas à aprendizagem, influências essas derivadas dos processos cognitivos, da aquisição de conteúdos e sistematização dos conhecimentos, tão bem explorados por Vigotski.

Diante dessas informações todas, como entender e auxiliar os alunos em suas dificuldades de aprendizagem ligadas ao ensino de Ciências e Biologia, principalmente, àquela de nosso interesse, relacionada ao estudo da evolução biológica dos seres vivos?

Pois bem, sendo os currículos escolares organizados sob influência da teoria da Evolução, e sem questionar a importância desse tema, o que observamos é uma prevalência das dificuldades dos alunos em resolver problemas e interpretar fenômenos biológicos em termos evolutivos darwinistas, mesmo após instrução formal (CLOUGH; WOODROBINSON, I985; BISHOP; ANDERSON, I990; BIZZO, I994; DEMASTES; SETTLAGE; GOOD, I995; JENSEN; FINLEY, 1996; SINCLAIR; PENDARVIS; BALDWIN, 1997; ALTERS; NELSON, 2002). O que se observa é a permanência de boa parte dos estudantes no limiar dos conceitos espontâneos sobre o assunto, não promovendo nos muitos casos estudados a transposição conceitual esperada pelos professores após todo um ciclo de aulas ou sequências didáticas realizadas. 
Os estudos de TRIVELATO JR (1995) mostram que o ensino que procurava conflitar as ideias dos alunos com contraexemplos ou experiências realizadas cientificamente sequer arranhava a concepção dos alunos. $\mathrm{Na}$ maioria dos casos, os alunos moldam os resultados dos experimentos à sua concepção ou criam "teorias" próprias para aquele conhecimento, não o incorporando a uma rede mais ampla de conhecimento. Assim, as explicações dadas pelos alunos para situações concretas do cotidiano continuam atreladas a uma rede de conhecimentos espontâneos, pessoal e própria de cada um (afinal esse é o único conhecimento digno de confiança para as pessoas), não considerando as teorias científicas “aprendidas" na escola. (GIORDAN, I988, p.55; ASTOLFI, I994; DRIVER, I988; CUBERO, 1989).

Sabemos e reconhecemos que a instrução formal não tem, ou melhor, não pode ter a pretensão de promover total e plena elevação conceitual em níveis superiores quando os alunos entram em contato com os mais diferentes conteúdos curriculares. $O$ que impressiona é a quantidade geral de alunos que mantêm explicações baseadas unicamente nas concepções espontâneas para fenômenos biológicos cotidianos.

Quando estes alunos encontram-se numa situação formal de aprendizagem como no período das avaliações tradicionais escolares a tentativa do aluno em explicar um fenômeno biológico através da evolução se mostra, apesar das muitas incorreções formais, mais presente. Nesta situação o aluno é pressionado pelo sistema escolar a dar uma resposta próxima da esperada daquilo que foi ensinado em aula. Se, em outras situações, menos formais que as escolares, ele se confrontar com os mesmos casos de fenômenos biológicos cobrados nas provas escolares, cuja explicação se esperaria dentro da teoria da Evolução, ele dificilmente reconhece ali essa oportunidade. Eduardo F. Mortimer atribuiria a isso uma indicação da falta de consciência do aluno de seu próprio perfil conceitual (MORTIMER, 2006, p. 79). De fato, o número de estudos sobre as concepções que os alunos possuem para interpretar grande parte dos fenômenos e conceitos estudados nas diversas áreas das ciências é enorme (PFUNDT e DUIT, 1994).

Os estudos de POZO e CRESPO (2009) sobre as concepções espontâneas mantidas pelos estudantes baseiam-se no reconhecimento de que estas concepções são muito persistentes - mantêm-se mesmo após muitos anos de instrução -, generalizadas - são 
compartilhadas por pessoas de diversas culturas, idades e níveis educacionais - de caráter mais implícito do que explícito - os alunos a utilizam, mas muitas vezes são incapazes de verbalizá-las -, relativamente coerentes - uma vez que o aluno as utiliza para enfrentar situações diversas - em alguns casos guardam uma notável semelhança com concepções já superadas na própria história das disciplinas científicas. Bons exemplos disso são as “eternas” explicações lamarckistas para a resistência bacteriana aos antibióticos e o "surgimento" das novas doenças virais.

BACHELARD (1996) chega às vias de considerar, veementemente, o conhecimento geral como obstáculo ao conhecimento científico. Segundo ele, "nada prejudicou tanto o progresso do conhecimento científico quanto a falsa doutrina do geral, que dominou de Aristóteles a Bacon, inclusive, e que continua sendo, para muitos, uma doutrina fundamental do saber". É de Bachelard a ideia de "noção de perfil epistemológico", onde o autor mostra que uma única doutrina filosófica não é suficiente para descrever todas as diferentes formas de pensar quando se tenta expor e explicar um simples conceito (BACHELARD, 1996, p. 89).

As concepções espontâneas não são algo acidental ou conjuntural, apresentam uma natureza estrutural, sistemática. São o resultado, como Vigotski caracterizou, de uma mente ou um sistema cognitivo que tenta dar sentido a um mundo definido não apenas pelas relações entre os objetos físicos que povoam o mundo, mas também pelas relações sociais e culturais que se estabelece em torno desses objetos. Fica claro, portanto, que seja tão difícil "livrar-se" delas no ensino, dado que constituem boa parte do nosso senso comum e, inclusive, da nossa tradição cultural (POZO; CRESPO, 2009, p.95).

\section{CONSIDERAÇÕES FINAIS}

Quando Vigotski observa o curso do desenvolvimento da criança na idade escolar e o processo de sua aprendizagem, vê que toda matéria de ensino sempre exige da criança mais do que ela pode dar hoje, ou seja, na escola a criança desenvolve uma atividade que a obriga a colocar-se acima de si mesma. Ele considera isso um sadio ensino escolar. A presença desse constante desafio estimula as funções desencadeantes do processo de aprendizagem. Porque na escola a criança não aprende o que sabe fazer sozinha, mas o que ainda não sabe e lhe vem 
a ser acessível em colaboração com o professor e sob sua orientação. Diante disso, a zona de desenvolvimento imediato, que determina esse campo das transições acessíveis à criança, é a que representa o momento mais determinante na relação da aprendizagem com o desenvolvimento.

As múltiplas influências da aprendizagem sobre o desenvolvimento e as também múltiplas influências do desenvolvimento sobre a aprendizagem da criança a acompanha durante toda sua trajetória escolar. É inerente ao ensino. A disciplina formal de cada matéria escolar (gramática, álgebra, ciências, biologia, física, química, entre outras) é o campo em que se realiza essa influência da aprendizagem sobre o desenvolvimento. Daí a aprendizagem ser mais frutífera quando se realiza nos limites de um período determinado pela zona de desenvolvimento imediato, também chamado de sensível esse período. $O$ reconhecimento dos períodos sensíveis ao aprendizado pelos professores pode além de contribuir, maximizar as influências sobre ele. Isso não é trivial. Os trabalhos de Maria Montessori (1870-1952) postulam ideias e dinâmicas pedagógicas dentro dessa linha.

O nosso aluno adolescente, carregado dessas influências mútuas, em plena fase de transitoriedade conceitual, ou seja, ora oscila entre o pensamento por complexos, ora oscila entre o pensamento por conceitos, precisa dar sentido ao mundo que o rodeia, um mundo cheio de objetos e pessoas. As concepções espontâneas, segundo POZO e CRESPO (2009) não são um problema a mais, e sim outra manifestação do mesmo problema, que tem dimensões atitudinais, procedimentais e conceituais: a desconexão entre o conhecimento que os alunos geram para dar sentido ao mundo que os rodeia e o conhecimento científico, infestado de estranhos símbolos e conceitos abstratos referentes a um mundo mais imaginário que real.

Assim, a problemática enfrentada pela temática da teoria da Evolução Biológica, não é diferente daquela enfrentada pela força newtoniana, calor e energia na Física como também pelos conceitos de átomo, estados e mudanças químicas e físicas da matéria em Química. Todas se situam em níveis mais ou menos profundos dos conceitos espontâneos preferidos pelos alunos quando confrontados pelos conceitos científicos (MORTIMER, 1994).

Concordamos com Vigotski quando diz que entre o desenvolvimento dos conceitos espontâneos e o dos científicos existem relações absolutamente análogas. $O$ 
desenvolvimento dos conceitos tanto espontâneos quanto científicos é no fundo, apenas uma parte do desenvolvimento da língua, exatamente o seu aspecto semântico, porque, em termos psicológicos, o desenvolvimento dos conceitos e o desenvolvimento dos significados da palavra são o mesmo processo apenas com nome diferente. Por isso, não cabe a ideia de substituição de um pelo outro, no sentido de que os conceitos espontâneos devem ser substituídos por conceitos científicos cujas ideias do mundo são mais aceitáveis.

Por mais rigor que se tenha, na ciência nunca se alcança o conhecimento verdadeiro no sentido que de que reproduza exatamente o mundo real. O que temos são modelos cada vez mais complexos e potentes para prever, explicar e simular a estrutura do mundo.

A proposta que melhor nos convence no sentido de auxiliar os alunos a lidarem com essas dificuldades em relacionar seus conceitos espontâneos e científicos onde um não conflitue com o outro é recorrer a diferentes modos de expor o currículo de ciências. A integração entre ambas as formas de conhecimento, assim como POZO e CRESPO (2009) descrevem, mais do que a substituição de uma pela outra, na tentativa de melhor compreender sua natureza faz-se necessário repassar as diversas formas de entender as relações entre o conhecimento cotidiano, que se dão não só de modo explícito na pesquisa, mas principalmente de modo implícito nas salas de aula, por meio da prática cotidiana no aprendizado e no ensino das ciências.

O aspecto particular levantado pela temática da teoria da Evolução Biológica no contexto escolar corrobora todos os outros estudos já realizados nas mais diferentes áreas das ciências referentes a resistência dos estudantes em reconhecer também como válidas e pertinentes os conhecimentos derivados dos conceitos científicos e fazer uso deles também em sua interpretação de fenômenos biológicos, ou seja, apropriar-se desses conhecimentos numa verdadeira tomada de consciência

\section{REFERÊNCIAS BIBLIOGRÁFICAS}

ASTOLFI, J.P. El trabajo didáctico de los obstáculos, em el corazón de los aprendizajes científicos. Enseñanza de las Ciencias, v. 12, n.2, 1994.

BACHELARD, G. A formação do espírito científico. Rio de Janeiro: Contraponto, 1996. 
BASTOS, F. O conceito de célula viva entre os alunos de segundo grau. Em Aberto, v.II, n.55, p.63-69, 2009.

BELL, B.F. e PEARSON, J. Better learning. International Journal of Science Education, I4 (3), pp.349-36r, 1992.

BISHOP, B.A. \& ANDERSON, C.W. Student conception of natural selection and its role in evolution. Journal of Research in Science Teaching, v. 27, n. 5, pp. 415-427, 1990.

BIZZO, N.M.V. From Down House Landlord to Brazilian high school students: What has happened to evolutionary knowledge on the way. Journal of Research in Science Teaching, v. 31, n. 5, pp. 517-556, 1994 .

BRASIL. Orientações curriculares para o ensino médio. Ciências da natureza, matemática e suas tecnologias/Secretaria de Educação Básica. Brasília: Ministério da Educação, Secretaria de Educação Básica, v.2, 2006.

BREM, S. K.; RANNEY, M. \& SCHINDEL, J. Perceived consequences of evolution: College students perceive negative personal and social impact in evolutionary theory. Science Education, v. 87, pp. I8I-206, 2003.

CLOUGH, E.E. \& WOOD-ROBINSON, C. How secondary students interpret instances of biological adaptation. Journal of Biological Education, v. 19, n. 2, pp. 125-130, 1985.

COBERN, W. W. Point: Belief, understanding, and the teaching of evolution. Journal of Research in Science Teaching, v. 31, pp. 583-590, 1994.

COBERN, W. W. Worldview theory and conceptual change in science education. Science Education, v. 8o, n. 5, pp. 579-610, 1996.

CUBERO, R. Como trabajar com las ideas de los alumnos. Diada editoras, Sevilla, 1989.

DEMASTES, S.S.; SETTLAGE, J. \& GOOD, R. Students' conceptions of natural selection and its role in evolution: Cases of replication and comparison. Journal of Research in Science Teaching, v. 32, n. 5, pp.535-50, 1995.

DRIVER, R. Un enfoque constructivista para el desarrollo del currículo em ciências. Enseñanza de las Ciencias, v.6, n.2, 1988. 
GIODAN, A., DE VECCHI, G. Los orígenes del saber: de las concepciones personales a los conceptos científicos. Sevilla: Diada, 1988.

JENSEN, M.S. \& FINLEY, F. N. Changes in student's understanding of 165 evolution resulting from different curricular and Instructional Strategies. Journal of Research in Science Teaching, v. 33, n. 8, pp. 879-900, 1996.

MARANDINO, M. Ensino de Biologia: histórias e práticas e diferentes espaços educativos. São Paulo: Cortez, 2009.

MAYR, E. O Desenvolvimento do Pensamento Biológico. Brasília: Editora Universidade de Brasília, 1998.

MEYER, D. \& EL-HANI, C.N. Evolução: o sentido da Biologia. São Paulo: Editora UNESP, 2005 .

MORTIMER, E.F. Construtivismo, mudança conceitual e ensino de ciências: para onde vamos? In: ESCOLA DE VERÃO FEUSP, 3, 1994, Serra Negra. Caderno de Textos. São Paulo: FEUSP, 1994. p.56-74.

MORTIMER, E.F. Linguagem e formação de conceitos no ensino de ciências. Belo Horizonte: Ed. UFMG, 2000.

POZO, J.I \& CRESPO, M.A.G. A aprendizagem e o ensino de ciências: do conhecimento cotidiano ao conhecimento científico. 5 ed. Porto Alegre: Artmed, 2009.

SEPULVEDA. C. \& EL-HANI, C. N. Apropriação do discurso científico por alunos protestantes de Biologia: Uma análise à luz da teoria da linguagem de Bakhtin. Investigações em Ensino de Ciências, v. II, n. I, pp. 29-5I, 2006.

SEPULVEDA. C. \& EL-HANI, C. N. Quando visões de mundo se encontram: Religião e ciência na trajetória de formação de alunos protestantes de uma Licenciatura em Ciências Biológicas. Investigações em Ensino de Ciências, v. 9, n. 2, pp. 137-175, 2004.

SINCLAIR, A.; PENDARVIS, M. P. \& BALDWIN, B. The relationship between college zoology students' beliefs about evolutionary theory and religion. Journal of Research and Development in Education, v. 30, n. 2, p. II8-25, 1997. 
SMITH, M.U.; SIEGEL, H. \& McINERNEY, J.D. Foundational issues in evolution education. Science \& Education, v.4, pp. 23-46, 1995.

TRIVELATO JR., J. Concepções de alunos sobre fungos e bactérias: subsídios para o ensino. São Paulo: FEUSP, 1995. (Série Textos - Pesquisa para o ensino de Ciências, n.6).

VIGOTSKI, L.S. A construção do pensamento e da linguagem. São Paulo. Martins Fontes: 2010. 